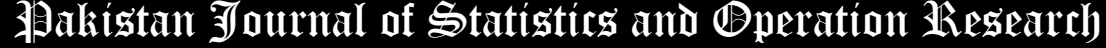

\section{Optimum Method for Determining Weibull Distribution Parameters Used in Wind Energy Estimation}

\author{
Nil Aras ${ }^{1}$, Ulku Erisoglu ${ }^{2 *}$, Hasan D. Y1ldıay ${ }^{3}$ \\ * Corresponding Author \\ 1. Eskişehir Technical University, Engineering Faculty, Department of Industrial Engineering, Eskişehir, 2655, \\ Turkey, nila@Eskișehir.edu.tr \\ 2. Necmettin Erbakan University, Department of Statistics, Faculty of Science, Konya, 42090, Turkey, \\ ugokal@erbakan.edu.tr \\ 3. Dumlupınar University, Engineering Faculty, Department of Mechanical Engineering, Kütahya, 43100, \\ Turkey, hasan.yildizay@dpu.edu.tr
}

\begin{abstract}
One of the well-known methods for the determination of wind energy potential is the two-parameter Weibull distribution. It is clear that the success of the Weibull distribution for wind energy applications depends on the estimation of the parameters which can be determined by using various numerical methods. In the present study, Monte Carlo simulation method is performed by using six parameters estimation method that is used in the estimation of Weibull distribution parameters such as Maximum Likelihood Estimation (MLE), Least Squares Method (LSM), Method of Moments (MOM), Method of Logarithmic Moments (MLM), Percentile Method (PM), and L-Moment Method (LM), and is compared to Mean Squared Error (MSE) and Mean Absolute Percentage Error (MAPE). In this study, the wind energy potential of the Meşelik region in Eskişehir was modeled with two-parameter Weibull distribution. The average wind speed $(\mathrm{m} / \mathrm{s})$ data, which are gathered in 10 minute intervals from the measuring device installed 10 meters about the ground in Meşelik Campus of Eskişehir Osmangazi University, is used. As a result of the simulation study, it has been determined that MLE is the best parameter estimation method for two-parameter Weibull distribution in large sample sizes, and LM has the closest performance to MLE. The wind speed $(\mathrm{m} / \mathrm{h})$ data of the region has been successfully modeled with twoparameter Weibull distribution and the highest average wind power density has been obtained in July as 49.38295 $\left(\mathrm{W} / \mathrm{m}^{2}\right)$ while the lowest average wind power density has been obtained in October as $19.30044\left(\mathrm{~W} / \mathrm{m}^{2}\right)$.
\end{abstract}

Key Words: Wind speed; Wind Power Density; Weibull Distribution; Maximum Likelihood Method; L-Moment Method; Wind Data.

Mathematical Subject Classification: 62F10

\section{Introduction}

In converting the wind potential to electrical energy, the wind speed distribution in the turbine installed area plays an important role along with wind turbine parameters. In the design of the system that will optimize the energy generation costs in practice, correct modeling of the wind regime in the area is crucial. The most commonly preferred method for the modeling of the frequency distribution of wind speeds is the Weibull distribution. Examining the literature, there are several studies in which the wind potential of an area is determined through Weibull distribution (by Carta et al., 2009). Literature research indicates that many studies have been carried out to determine wind energy potential in different regions through the Weibull distribution. The following were given a few studies in which wind energy potential was determined by the Weibull distribution.

The study carried out by Baseer et al. (2017) indicates the wind characteristics of seven sites in Jubail, Saudi Arabia through the Weibull distribution function. Within their study, they have collected five years' wind data from six locations and three years' data from one location both of which have been gathered at a height of 10 meters. Baseer 
et al. (2017) have utilized the maximum likelihood, the least-squares methods, and the WASP algorithm to determine the parameters of the Weibull distribution. They have indicated that the maximum likelihood method is better than others in the prediction of the Weibull parameters. Novoa et al. (2017) have analyzed the daily wind speed data collected from 46 automatic weather stations in Navarre, northern Spain via Weibull distribution. They have indicated that $23 \%$ of the regions had adequate wind resources for the installation of wind turbines. Shoaib et al. (2017) have analyzed wind speed data gathered at five different heights through Weibull distribution at Baburband. They have expressed that the region has $278 \mathrm{~W} / \mathrm{m} 2$ wind power potential at Baburband site. Wais (2017) has compared 2 and 3 parameter Weibull distributions in order to design a model for wind speed data in the 3 different turbine sites. The results have indicated that for the higher likelihood of the null wind, the 3-parameter Weibull distribution yields better results compared to the 2-parameter Weibull distribution. Akdağ and Güler (2018) have offered a new method called alternative moment method for estimating the Weibull parameters in the assignation of the wind energy potential. They have compared the efficacy of the offered method with commonly used parameter estimation methods. The comparison has indicated that the offered method is better than Justus moment and novel energy pattern factor methods. Furthermore, they have predicted the wind energy potential data collected from 16 different weather stations located around Spain through the offered method. Soulouknga et al. (2018) have calculated the wind energy potential of Faya-Largeau via the Weibull distribution for the wind speed data gathered at 10 meters height. They have predicted that the annual values of the Weibull shape and scale parameters are respectively 3.75 and $3.60(\mathrm{~m} / \mathrm{s})$ while the power density and available energy are $343.31 \mathrm{~W} / \mathrm{m}^{2}$ and $249.87 \mathrm{kWh} / \mathrm{m}^{2}$, respectively. Ali et al. (2018) have predicted the wind energy potential of the Deokjeok-do Island Incheon (South Korea) via Weibull distribution. They have utilized the wind data gathered at 10 meters' height, including wind speed and wind direction for 17 years (2000-2016). Kantar et al. (2018) have come up with the extended generalized Lindley distribution as an alternative to the Weibull distribution to assess wind energy potential. They have analyzed the performance of the offered alternative distribution method for the wind speed data collected at four stations in Turkey.

Wind speed and direction data are needed to determine the wind energy potential of a site for energy generation purposes. Therefore, the wind speed and direction values should be measured periodically in conformity with the standards by installing wind measurement station(s) in a suitable place or places in the region. Wind energy is predominantly a nonsynchronous generation source. The project design and economy of the wind power plant depend mainly on the amount of energy that could be generated at the selected plant site. Wind power curves play important roles in wind power forecasting. In order to determine this amount of energy, the data obtained from the wind measurements made in the energy production regions should be analyzed statistically (by Malvaldi et al., 2017). As a result of this analysis, a very important infrastructure will be formed for the wind turbines to be installed in the region by determining the annual average wind speed, dominant wind direction, average power density of the region (by Aras, 2003).

This study mainly aims to discover the wind potential of the region of Meşelik in Eskişehir through analyzing the wind data gathered between July 2013 and June 2014. The wind energy potential of the Meşelik region has been evaluated through two-parameter Weibull distribution in this study. In previous studies, where wind potential is analyzed by Weibull distribution, wind speed measurements obtained at a height of 10 meters were generally used. Therefore, in the evaluation of the wind potential of the area, the wind speed $(\mathrm{m} / \mathrm{h})$ data gathered in 10 minute intervals from the measuring device installed 10 meters above ground in the Meşelik Campus of Osmangazi University were used.

Within the study, a simulation study was carried out first to determine the optimal parameter estimation method in the estimation of Weibull distribution parameters. In the comparison of the estimation methods, mean square error (MSE) and mean absolute percentage error (MAPE) criteria were used. Following the selection of the most suitable parameter estimation method, the average wind speed $(\mathrm{m} / \mathrm{h})$ data obtained during the period July 2013 -June 2014 were modeled by month with two-parameter Weibull distribution. The wind characteristics calculated based on the obtained parameter Weibull distribution were compared with wind characteristics calculated based on the observation. Moreover, the compliance of wind speeds with two-parameter Weibull distribution modeling, were evaluated with the root of mean square error (RMSE) and the coefficient of determination $\left(\mathrm{R}^{2}\right)$ criteria.

The rest of this study is organized as follows: two-parameter Weibull distribution and wind characteristics based on two-parameter Weibull distribution are defined in the section 2. The six different parameter estimation methods for two-parameter Weibull distribution are presented in the section 3. Comparison of the parameter estimation methods 
using the Monte Carlo simulation method is given in section 4. The details about the data used for analysis and results derived from this study are discussed in section 5. Finally, some conclusions are noted in section 6.

\section{Weibull Distribution}

Probability density function (pdf) of two-parameter Weibull distribution is shown with the equation below:

$$
f_{w b l}(v)=\frac{k}{c}\left(\frac{v}{c}\right)^{k-1} \exp \left[-\left(\frac{v}{c}\right)^{k}\right]
$$

In Eq. 1; $\mathrm{v}$ represents observed wind speed, and $\mathrm{c}$ and $\mathrm{k}$ represent scale and shape factors, respectively. Cumulative Distribution Function (CDF) of Weibull is given in Eq. 2.

$$
\mathrm{F}_{\mathrm{wbl}}(\mathrm{v})=1-\exp \left[-\left(\frac{\mathrm{v}}{\mathrm{c}}\right)^{\mathrm{k}}\right]
$$

In the modeling of wind speed $(\mathrm{m} / \mathrm{h})$ data with two-parameter Weibull distribution, the mean wind speed and the standard deviation of the wind speeds that are determined based on two-parameter Weibull distribution are shown in Eqs. 3 and 4.

$$
\begin{gathered}
\overline{\mathrm{v}}_{\mathrm{wbl}}=\mathrm{c} \Gamma\left(1+\frac{1}{\mathrm{k}}\right) \\
\sigma_{\mathrm{wbl}}=\left\{\mathrm{c}^{2}\left[\Gamma\left(1+\frac{2}{\mathrm{k}}\right)-\Gamma^{2}\left(1+\frac{1}{\mathrm{k}}\right)\right]\right\}^{\frac{1}{2}}
\end{gathered}
$$

The $\Gamma($.$) in Eqs. 3$ and 4 represent the gamma function. As is known, the wind power potential of a wind turbine at $\mathrm{v}$ speed with a wing swept area of $\mathrm{A}$ is calculated as shown in Eq. 5.

$$
P(v)=\frac{1}{2} \rho A v^{3}
$$

In Eq. 5; $\rho$; is the air density and is calculated as $1.225 \mathrm{~kg} / \mathrm{m}^{3}$. Mean power density for two-parameter Weibull distribution is obtained with Eq. 6 below.

$$
\mathrm{P}_{\mathrm{wbl}}=\frac{1}{2} \rho c^{3} \Gamma\left(1+\frac{3}{\mathrm{k}}\right)
$$

\section{Parameter Estimation Methods}

Forecasting for wind energy is becoming more important as the amount of energy generated from wind increases (by Sweeney, 2020). In determining the wind energy potential of an area based on two-parameter Weibull distribution; firstly, c and k should be estimated. Numerous methods have been developed to estimate the parameters of twoparameter Weibull distribution. In this study; most commonly used methods, which are maximum likelihood estimation (MLE), least squares method (LSM), method of moments (MOM), method of logarithmic moments (MLM), percentile method (PM), and L-moment method (LM), will be examined.

\subsection{Maximum Likelihood Estimation (MLE)}

The log-likelihood function for two-parameter Weibull distribution is given by

$$
\ln L=n \ln k-n k \operatorname{lnc}+(\mathrm{k}-1) \sum_{\mathrm{i}=1}^{\mathrm{n}} \ln \mathrm{v}_{\mathrm{i}}-\mathrm{c}^{-\mathrm{k}} \sum_{\mathrm{i}=1}^{\mathrm{n}} \mathrm{v}_{\mathrm{i}}^{\mathrm{k}}
$$


In order to obtain the maximum likelihood estimations of two-parameter Weibull distribution, a log-likelihood function given in Eq. (7) must be derived according to parameters c and k, respectively, and equations obtained by equating them to zero must be solved.

$$
\begin{gathered}
\frac{\partial \ln L}{\partial c}=-\mathrm{nkc}^{-1}+\mathrm{kc}^{-\mathrm{k}-1} \sum_{\mathrm{i}=1}^{\mathrm{n}} \mathrm{v}_{\mathrm{i}}^{\mathrm{k}}=0 \\
\frac{\partial \ln \mathrm{L}}{\partial \mathrm{k}}=\mathrm{nk}^{-1}-\mathrm{nlnc}+\sum_{\mathrm{i}=1}^{\mathrm{n}} \ln \mathrm{v}_{\mathrm{i}}+\mathrm{c}^{-\mathrm{k}} \operatorname{lnc} \sum_{\mathrm{i}=1}^{\mathrm{n}} \mathrm{v}_{\mathrm{i}}^{\mathrm{k}}-\mathrm{c}^{-\mathrm{k}} \sum_{\mathrm{i}=1}^{\mathrm{n}} \mathrm{v}_{\mathrm{i}}^{\mathrm{k}} \ln \mathrm{nv}_{\mathrm{i}}=0
\end{gathered}
$$

Consequently, $\hat{\mathrm{k}}$ is obtained as the solution of

$$
k=\left[\frac{\sum_{i=1}^{n} v_{i}^{k} \ln v_{i}}{\sum_{i=1}^{n} v_{i}^{k}}-\frac{\sum_{i=1}^{n} \ln v_{i}}{n}\right]^{-1} .
$$

Despite the fact that the analytical solution is not present, $\hat{\mathrm{k}}$ could be readily solved through the iterative methods. In order to obtain the maximum likelihood estimation of $\mathrm{k}$ parameter of Weibull distribution, the Newton-Raphson method could be used (by Genc et al., 2005). In the $(r+1)^{\text {th }}$ iteration of Newton-Raphson method, maximum likelihood estimation of $\mathrm{k}$ shape parameter of Weibull distribution is obtained by the equation below.

$$
\hat{\mathrm{k}}_{(\mathrm{r}+1)}=\hat{\mathrm{k}}_{\mathrm{r}}+\frac{\mathrm{A}_{\mathrm{r}}+\left(1 / \hat{\mathrm{k}}_{\mathrm{r}}\right)-\left(\mathrm{C}_{\mathrm{r}} / \mathrm{B}_{\mathrm{r}}\right)}{\left(1+\hat{\mathrm{k}}_{\mathrm{r}}^{2}\right)+\left(\mathrm{B}_{\mathrm{r}} \mathrm{D}_{\mathrm{r}}-\mathrm{C}_{\mathrm{r}}^{2}\right) / \mathrm{B}_{\mathrm{r}}^{2}}
$$

Terms in Eq. 11 are defined as $A_{r}=\sum_{i=1}^{n} \ln v_{i} / n, B_{r}=\sum_{i=1}^{n} v_{i}^{\widehat{K}_{r}}, C_{r}=\sum_{i=1}^{n} v_{i}^{\widehat{k}_{r}} \ln v_{i}$ and $D_{r}=\sum_{i=1}^{n} v_{i}^{\widehat{k}_{r}}\left(l n v_{i}\right)^{2}$. Once $\mathrm{k}$ is estimated, the maximum likelihood estimation of $\mathrm{c}$ is obtained as follows:

$$
\widehat{c}=\left(\frac{\sum_{\mathrm{i}=1}^{\mathrm{n}} \mathrm{v}_{\mathrm{i}}^{\widehat{\mathrm{k}}}}{\mathrm{n}}\right)^{1 / \widehat{\mathrm{k}}}
$$

\subsection{Least Squares Method (LSM)}

Least squares estimations of two-parameter Weibull distribution parameters are obtained by using the linear relationship in Eq. (13) obtained by considering the natural logarithm of CDF in Eq. (2) twice.

$$
\ln \left(-\ln \left\{1-\mathrm{F}_{\mathrm{wbl}}\left(\mathrm{v}_{\mathrm{i}}\right)\right\}\right)=\mathrm{k} \ln \left(\mathrm{v}_{\mathrm{i}}\right)-\mathrm{k} \ln (\mathrm{c})
$$

When the term $\ln \left(-\ln \left\{1-\mathrm{F}_{\text {wbl }}\left(\mathrm{v}_{\mathrm{i}}\right)\right\}\right)$ in Eq. (13) is defined as $\mathrm{y}_{\mathrm{i}}$, the least-squares estimates of shape and scale parameters of the Weibull distribution are respectively as follows;

$$
\begin{gathered}
\hat{\mathrm{k}}=\frac{\mathrm{n} \sum_{\mathrm{i}=1}^{\mathrm{n}} \hat{\mathrm{y}}_{\mathrm{i}} \ln \left(\mathrm{v}_{\mathrm{i}}\right)-\sum_{\mathrm{i}=1}^{\mathrm{n}} \ln \left(\mathrm{v}_{\mathrm{i}}\right) \sum_{\mathrm{i}=1}^{\mathrm{n}} \hat{\mathrm{y}}_{\mathrm{i}}}{\mathrm{n} \sum_{\mathrm{i}=1}^{\mathrm{n}} \ln \left(\mathrm{v}_{\mathrm{i}}\right)^{2}-\left\{\sum_{\mathrm{i}=1}^{\mathrm{n}} \ln \left(\mathrm{v}_{\mathrm{i}}\right)\right\}^{2}} \\
\hat{\mathrm{c}}=\exp \left(\frac{\sum_{\mathrm{i}=1}^{\mathrm{n}} \ln \left(\mathrm{v}_{\mathrm{i}}\right)}{\mathrm{n}}-\frac{\sum_{\mathrm{i}=1}^{\mathrm{n}} \hat{\mathrm{y}}_{\mathrm{i}}}{\hat{\mathrm{k}} \mathrm{n}}\right) .
\end{gathered}
$$

The term $\hat{y}_{\mathrm{i}}$ in Eqs. 14 and 15 is the estimated value obtained by using the cumulative distribution function instead of the $\mathrm{F}_{\text {wbl }}\left(\mathrm{v}_{\mathrm{i}}\right)$ in $\mathrm{y}_{\mathrm{i}}=\ln \left(-\ln \left\{1-\mathrm{F}_{\text {wbl }}\left(\mathrm{v}_{\mathrm{i}}\right)\right\}\right)$ equation. In this study, the median rank value $(\mathrm{i}-0.3) /(\mathrm{n}+0.4)$ has been used as an empirical cumulative distribution function. 


\subsection{Method of Moments (MOM)}

Parameter estimations in the method of moments are carried out by solving the equations obtained by equating the sample moments as many as unknown parameters to the population moments (by Karakoca et al., 2015). The first two raw moments of two-parameter Weibull distribution are defined as $\mathrm{M}_{1}=\mathrm{c} \Gamma(1+1 / \mathrm{k})$ and $\mathrm{M}_{2}=\mathrm{c}^{2} \Gamma(1+$ $2 / \mathrm{k})$. The first two raw moments based on a sample are calculated with $\mathrm{m}_{1}=\left(\sum_{\mathrm{i}=1}^{\mathrm{n}} \mathrm{v}_{\mathrm{i}}\right) / \mathrm{n}$ and $\mathrm{m}_{2}=\left(\sum_{\mathrm{i}=1}^{\mathrm{n}} \mathrm{v}_{\mathrm{i}}^{2}\right) / \mathrm{n}$ equations. The moment's estimation of $\mathrm{k}$ is obtained by solving the Eq. (16):

$$
\frac{\mathrm{M}_{1}^{2}}{\mathrm{M}_{2}}-\frac{\mathrm{m}_{1}^{2}}{\mathrm{~m}_{2}}=0
$$

Newton-Raphson, an iterative method, can be used for solving Eq. (16). In the $(r+1)^{\text {th }}$ iteration of NewtonRaphson method, moments estimation of $\mathrm{k}$ shape parameter of Weibull distribution is obtained with the equation below.

$$
\widehat{\mathrm{k}}_{\mathrm{r}+1}=\hat{\mathrm{k}}_{\mathrm{r}}-\frac{\mathrm{P}_{\mathrm{r}}}{\mathrm{Q}_{\mathrm{r}}}
$$

The terms $P_{r}$ and $Q_{r}$ are defined as

$$
\begin{gathered}
\mathrm{P}_{\mathrm{r}}=\frac{\Gamma^{2}(1+1 / \hat{\mathrm{k}})}{\Gamma(1+2 / \hat{\mathrm{k}})}-\frac{\mathrm{m}_{1}^{2}}{\mathrm{~m}_{2}} \\
\mathrm{Q}_{\mathrm{r}}=\frac{2 \Gamma^{2}\left(1+1 / \hat{\mathrm{k}}_{\mathrm{r}}\right)\left\{\psi\left(1+2 / \hat{\mathrm{k}}_{\mathrm{r}}\right)-\psi\left(1+1 / \hat{\mathrm{k}}_{\mathrm{r}}\right)\right\}}{\hat{\mathrm{k}}_{\mathrm{r}}^{2} \Gamma\left(1+2 / \hat{\mathrm{k}}_{\mathrm{r}}\right)}
\end{gathered}
$$

respectively, where $\psi($.$) is the digamma function. Moment's estimation of c scale parameter of Weibull distribution$ is calculated with Eq. (20) below.

$$
\widehat{\mathrm{c}}=\frac{\mathrm{m}_{1}}{\Gamma(1+1 / \hat{\mathrm{k}})}
$$

\subsection{Method of Logarithmic Moments (MLM)}

The method of logarithmic moments is a special form of the method of moments. Logarithmic moment's estimates of two-parameter Weibull distribution parameters are obtained as shown below (by Teimouri et al., 2013).

$$
\begin{gathered}
\hat{\mathrm{k}}=\left(\frac{\pi^{2}}{6 \mathrm{~S}^{2}}\right)^{1 / 2} \\
\hat{\mathrm{c}}=\exp \left(\frac{\hat{\mathrm{k}} \overline{\mathrm{x}}+\gamma}{\hat{\mathrm{k}}}\right)
\end{gathered}
$$

In Eqs. 21 and 22, $S^{2}$ and $\bar{x}$ are sample variance and the sample mean, respectively, for transformed data obtained by taking the natural logarithm of wind speed data. Also, the term $\gamma$ shows the Euler constant.

\subsection{Percentile Method (PM)}

In two-parameter Weibull distribution, the quantile function that gives the equivalent wind speed value of cumulative distribution function $\mathrm{p}$ is defined with the equation below

$$
\mathrm{v}_{\mathrm{p}}=\mathrm{c}[-\ln (1-\mathrm{p})]^{1 / \mathrm{k}}
$$


Percentile estimations of two-parameter Weibull distribution are obtained by equating the equations of two selected $\mathrm{p}$ values in quantile function to relevant observed wind speed. Percentile estimation of $\mathrm{c}$ scale parameter of Weibull distribution could be simply obtained by selecting $p=1-\exp (-1) \cong 0.632$ in Equation (23).

$$
\widehat{c}=v_{1-\exp }(-1)
$$

The percentile estimation of $\mathrm{k}$ is obtained with the equation below:

$$
\widehat{\mathrm{k}}=\left(\frac{\ln [-\ln (1-\mathrm{p})]}{\ln \left(\mathrm{v}_{\mathrm{p}}\right)-\ln (\hat{\mathrm{c}})}\right)
$$

where $0<v_{p}<v_{0.632}$ should be taken (by Marks, 2005). There are several proposals for the determination of the optimum value of $p$ in Eq. (25). In the present study, $p=0.15$ value, proposed by Wang and Keats (1995) has been used.

\subsection{L-Moment Method (LM)}

The L-moment estimation method is based on the $\mathrm{r}^{\text {th }}$ moment of ith order statistics. As with the method of moments, parameter estimations are performed by solving the equations obtained by equating population L-moments to sample L-moments (by Erisoglu and Erisoglu, 2014). Population L-moment $\mu_{\mathrm{r}}^{0}$ is defined as in Eq. (26).

$$
\mu_{\mathrm{r}}^{0}=\frac{1}{\mathrm{r}} \sum_{\mathrm{k}=0}^{\mathrm{r}-1}(-1)^{\mathrm{k}} \mathrm{C}_{\mathrm{k}}^{\mathrm{r}-1} \mathrm{E}\left(\mathrm{X}_{\mathrm{r}-\mathrm{k}: \mathrm{r}}\right) \quad \mathrm{r}=1,2,3, \ldots
$$

In Eq. 24; $C_{i}^{n}=n ! /(i !(n-i) !)$ shows the binomial coefficient and the term $X_{i: n}$ shows ith order statistics in $n$ sample size. Sample L-moments are calculated with the equation below.

$$
\mathrm{m}_{\mathrm{r}}^{0}=\frac{1}{\mathrm{r}} \sum_{\mathrm{i}=1}^{\mathrm{n}} \frac{\sum_{\mathrm{k}=0}^{\mathrm{r}-1}(-1)^{\mathrm{k}} \mathrm{C}_{\mathrm{k}}^{\mathrm{r}-1} \mathrm{C}_{\mathrm{k}}^{\mathrm{n}-\mathrm{i}} \mathrm{C}_{\mathrm{r}-\mathrm{k}-1}^{\mathrm{i}-1}}{\mathrm{C}_{\mathrm{r}}^{\mathrm{n}}} \mathrm{X}_{\mathrm{i}: \mathrm{n}}
$$

L-moment estimations of shape (k) and scale (c) parameters are obtained as below, respectively.

$$
\begin{gathered}
\hat{\mathrm{k}}=\frac{\ln (2)}{\ln \left(1-\frac{\mathrm{m}_{2}^{0}}{\mathrm{~m}_{1}^{0}}\right)} \\
\hat{\mathrm{c}}=\frac{\mathrm{m}_{1}^{0}}{\Gamma(1+1 / \hat{\mathrm{k}})}
\end{gathered}
$$

In Eqs. 26 and 27; $\mathrm{m}_{1}^{0}$ and $\mathrm{m}_{2}^{0}$ are sample L-moments and calculated using $\mathrm{m}_{1}^{0}=\frac{\sum_{\mathrm{i}=1}^{\mathrm{n}} \mathrm{v}_{\mathrm{i}: \mathrm{n}}}{\mathrm{n}}$ and $\mathrm{m}_{2}^{0}=$ $\frac{2 \sum_{\mathrm{i}=1}^{\mathrm{n}}(\mathrm{i}-1) \mathrm{v}_{\mathrm{i}: \mathrm{n}}}{\mathrm{n}(\mathrm{n}-1)}-\mathrm{m}_{1}^{0}$ equations.

\section{Simulation}

In this part, the performances of examined parameter estimation methods in the estimation of Weibull distribution parameters have been compared with the simulation study. In the simulation study, 10.000 data sets have been generated from two-parameter Weibull distribution for the selected parameter values and different sample sizes $(\mathrm{n}=$ $10,30,50$ ve 100). The chosen parameter values are decided according to parameter prediction values which are prevalent in the literature. In the Newton-Raphson iterations, the number of iterations is not restricted, and for convergence, the difference between 2 successive predictions is supposed to be smaller than $10^{-4}$ value. 
Comparing the performances of parameter estimation methods, MSE and MAPE criteria are taken into consideration. MSE and MAPE values are respectively defined with equations below.

$$
\begin{aligned}
\operatorname{MSE}(\theta) & =\frac{1}{10000} \sum_{\mathrm{i}=1}^{10000}\left(\theta-\hat{\theta}_{\mathrm{i}}\right)^{2} \\
\operatorname{MAPE}(\theta) & =\frac{1}{10000} \sum_{\mathrm{i}=1}^{10000} \frac{100\left|\theta-\hat{\theta}_{\mathrm{i}}\right|}{\theta}
\end{aligned}
$$

In Eqs. 30 and 31; the term $\theta$ indicates one of the unknown parameters of Weibull distribution (c and k), and the term $\widehat{\theta}_{\mathrm{i}}$ indicates the estimated value of the unknown $\theta$ parameter in the ith step of the simulation. The lower MSE and MAPE values' means that the parameter estimation method has a good efficiency. The codes of the present study comparing the parameter estimation methods for two-parameter Weibull distribution are written in MATLAB software. Averages of parameter estimations obtained by different parameter estimation methods in different sample sizes have been presented in Table 1 .

Examining Table 1; the efficiency of parameter estimation methods increases as the sample size volume increases, and averages of parameter estimations are observed to converge closer to actual parameter values. The comparison of parameter estimation methods for two-parameter Weibull distribution for different $k$ parameter values to average of MAPE values calculated for two-parameters of the distribution is presented in Figure 1.
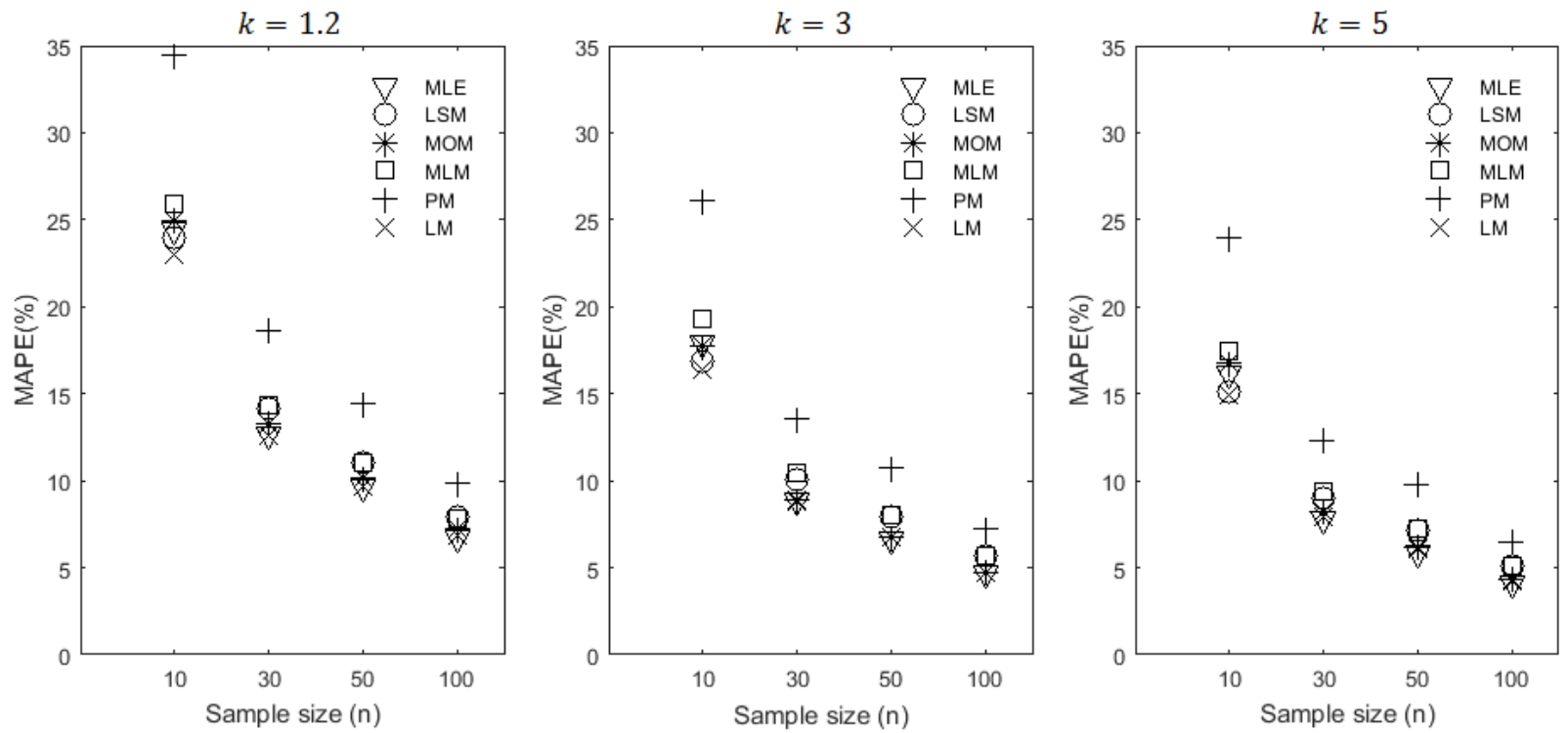

Figure 1: The comparison of parameter estimation methods with the mean MAP criteria

Examining the Figure 1; according to the mean MAPE criterion, in small sample size $(n=10)$, LM method is seen to have better performance than other parameter methods. In other $\operatorname{sample} \operatorname{sizes}(n=30,50$ ve 100), MLE method is the most successful parameter estimation method according to mean MAPE criterion. According to the MAPE criterion, the performance of the PM method was found significantly poor than other parameter estimation methods. According to the MAPE criterion, LM parameter estimation method is considered as the best alternative for MLE method.

The averages of the MSE values obtained for parameters of the distribution with different parameter estimation methods for two-parameter Weibull distribution in different sample sizes are presented in Table 2. Examining Table 2; according to the mean MSE criterion, LM method in small sample sizes, and MLE method in large sample sizes are found to be the best performing methods in parameter estimations of two-parameter Weibull distribution. As a result of the simulation study; it is determined that MLE is the best parameter estimation method for parameter estimation of two-parameter Weibull distribution in large sample sizes, and LM has the closes performance to MLE. 
Table 1: Averages of parameter estimations of two-parameter Weibull distribution obtained by different parameter estimation methods in different sample sizes $c=2$ $c=4$ $c=8$

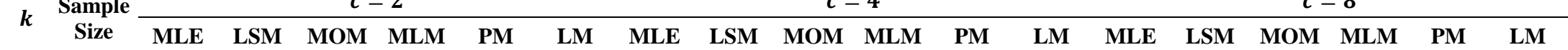

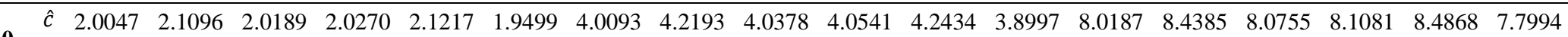

$\begin{array}{lllllllllllllllllllll}\hat{k} & 1.4042 & 1.1616 & 1.4439 & 1.3896 & 1.4423 & 1.2668 & 1.4042 & 1.1616 & 1.4439 & 1.3896 & 1.4423 & 1.2668 & 1.4042 & 1.1616 & 1.4439 & 1.3896 & 1.4423 & 1.2668\end{array}$ $\begin{array}{llllllllllllllllllllll}\hat{c} & 2.0015 & 2.0558 & 2.0063 & 2.0074 & 2.0949 & 1.9833 & 4.0029 & 4.1116 & 4.0127 & 4.0148 & 4.1897 & 3.9667 & 8.0059 & 8.2232 & 8.0253 & 8.0295 & 8.3795 & 7.9333\end{array}$

$\begin{array}{llllllllllllllllllll}30 & \hat{k} & 1.2568 & 1.1536 & 1.2754 & 1.2617 & 1.2546 & 1.2161 & 1.2568 & 1.1536 & 1.2754 & 1.2617 & 1.2546 & 1.2161 & 1.2568 & 1.1536 & 1.2754 & 1.2617 & 1.2546 & 1.2161\end{array}$ $\begin{array}{lllllllllllllllllllll}\hat{c} & 2.0028 & 2.0423 & 2.0061 & 2.0063 & 2.0029 & 1.9920 & 4.0056 & 4.0847 & 4.0121 & 4.0125 & 4.0058 & 3.9841 & 8.0113 & 8.1693 & 8.0242 & 8.0250 & 8.0115 & 7.9681\end{array}$

$\begin{array}{lllllllllllllllllllll}50 & \hat{k} & 1.2347 & 1.1618 & 1.2475 & 1.2385 & 1.2562 & 1.2108 & 1.2347 & 1.1618 & 1.2475 & 1.2385 & 1.2562 & 1.2108 & 1.2347 & 1.1618 & 1.2475 & 1.2385 & 1.2562 & 1.2108\end{array}$ $\begin{array}{llllllllllllllllllll}\hat{c} & 1.9996 & 2.0246 & 2.0012 & 2.0013 & 2.0185 & 1.9942 & 3.9991 & 4.0492 & 4.0025 & 4.0026 & 4.0370 & 3.9885 & 7.9982 & 8.0983 & 8.0050 & 8.0053 & 8.0740 & 7.9769\end{array}$

$\begin{array}{lllllllllllllllllllll}100 & \hat{k} & 1.2171 & 1.1720 & 1.2243 & 1.2192 & 1.1941 & 1.2053 & 1.2171 & 1.1720 & 1.2243 & 1.2192 & 1.1941 & 1.2053 & 1.2171 & 1.1720 & 1.2243 & 1.2192 & 1.1941 & 1.2053 \\ & & c & 1.9836 & 2.0241 & 1.9821 & 1.9921 & 2.0210 & 1.9887 & 3.9671 & 4.0482 & 3.9641 & 3.9843 & 4.0419 & 3.9774 & 7.9343 & 8.0963 & 7.9282 & 7.9685 & 8.0839 & 7.9547\end{array}$

$\begin{array}{lllllllllllllllllllll}\hat{c} & 1.9836 & 2.0241 & 1.9821 & 1.9921 & 2.0210 & 1.9887 & 3.9671 & 4.0482 & 3.9641 & 3.9843 & 4.0419 & 3.9774 & 7.9343 & 8.0963 & 7.9282 & 7.9685 & 8.0839 & 7.9547\end{array}$

$\begin{array}{llllllllllllllllllllll}10 & \hat{k} & 3.5105 & 2.9041 & 3.4811 & 3.4740 & 3.6059 & 3.1923 & 3.5105 & 2.9041 & 3.4811 & 3.4740 & 3.6059 & 3.1923 & 3.5105 & 2.9041 & 3.4811 & 3.4740 & 3.6059 & 3.1923\end{array}$ $\begin{array}{lllllllllllllllllllll}\hat{c} & 1.9945 & 2.0156 & 1.9939 & 1.9966 & 2.0280 & 1.9962 & 3.9889 & 4.0312 & 3.9878 & 3.9932 & 4.0560 & 3.9923 & 7.9779 & 8.0624 & 7.9757 & 7.9864 & 8.1121 & 7.9847\end{array}$

$\begin{array}{lllllllllllllllllllll}\hat{k} & 3.1421 & 2.8839 & 3.1336 & 3.1542 & 3.1364 & 3.0498 & 3.1421 & 2.8839 & 3.1336 & 3.1542 & 3.1364 & 3.0498 & 3.1421 & 2.8839 & 3.1336 & 3.1542 & 3.1364 & 3.0498\end{array}$

$\begin{array}{llllllllllllllllllllll}\hat{c} & 1.9974 & 2.0129 & 1.9971 & 1.9986 & 1.9954 & 1.9984 & 3.9948 & 4.0257 & 3.9941 & 3.9973 & 3.9909 & 3.9969 & 7.9897 & 8.0515 & 7.9883 & 7.9946 & 7.9818 & 7.9938\end{array}$

$\begin{array}{lllllllllllllllllllll}50 & \hat{k} & 3.0867 & 2.9046 & 3.0814 & 3.0962 & 3.1406 & 3.0317 & 3.0867 & 2.9046 & 3.0814 & 3.0962 & 3.1406 & 3.0317 & 3.0867 & 2.9046 & 3.0814 & 3.0962 & 3.1406 & 3.0317\end{array}$ $\begin{array}{llllllllllllllllllll}\hat{c} & 1.9979 & 2.0078 & 1.9978 & 1.9985 & 2.0045 & 1.9985 & 3.9959 & 4.0156 & 3.9956 & 3.9971 & 4.0089 & 3.9969 & 7.9918 & 8.0311 & 7.9911 & 7.9942 & 8.0179 & 7.9939\end{array}$

\begin{tabular}{lllllllllllllllllllllll}
100 & $\hat{k}$ & 3.0427 & 2.9299 & 3.0395 & 3.0479 & 2.9852 & 3.0148 & 3.0427 & 2.9299 & 3.0395 & 3.0479 & 2.9852 & 3.0148 & 3.0427 & 2.9299 & 3.0395 & 3.0479 & 2.9852 & 3.0148 \\
\hline
\end{tabular}

$\begin{array}{lllllllllllllllllll}\hat{c} & 1.9871 & 2.0113 & 1.9857 & 1.9922 & 2.0082 & 1.9950 & 3.9743 & 4.0227 & 3.9714 & 3.9845 & 4.0163 & 3.9900 & 7.9485 & 8.0453 & 7.9427 & 7.9689 & 8.0327 & 7.9801\end{array}$

$\begin{array}{llllllllllllllllllllll}10 & \hat{k} & 5.8509 & 4.8401 & 5.8533 & 5.7899 & 6.0098 & 5.3637 & 5.8509 & 4.8401 & 5.8533 & 5.7899 & 6.0098 & 5.3637 & 5.8509 & 4.8401 & 5.8533 & 5.7899 & 6.0098 & 5.3637\end{array}$ $\begin{array}{llllllllllllllllllll}\hat{c} & 1.9957 & 2.0083 & 1.9952 & 1.9969 & 2.0153 & 1.9982 & 3.9914 & 4.0166 & 3.9903 & 3.9939 & 4.0305 & 3.9965 & 7.9828 & 8.0332 & 7.9806 & 7.9878 & 8.0610 & 7.9930\end{array}$

$\begin{array}{llllllllllllllllllllll}30 & \hat{k} & 5.2368 & 4.8065 & 5.2400 & 5.2570 & 5.2274 & 5.0982 & 5.2368 & 4.8065 & 5.2400 & 5.2570 & 5.2274 & 5.0982 & 5.2368 & 4.8065 & 5.2400 & 5.2570 & 5.2274 & 5.0982\end{array}$

$\begin{array}{llllllllllllllllllllll} & \hat{c} & 1.9979 & 2.0071 & 1.9975 & 1.9986 & 1.9963 & 1.9994 & 3.9957 & 4.0142 & 3.9951 & 3.9971 & 3.9927 & 3.9988 & 7.9914 & 8.0283 & 7.9901 & 7.9943 & 7.9854 & 7.9976\end{array}$

$\begin{array}{lllllllllllllllllllll}50 & \hat{k} & 5.1445 & 4.8410 & 5.1453 & 5.1603 & 5.2343 & 5.0618 & 5.1445 & 4.8410 & 5.1453 & 5.1603 & 5.2343 & 5.0618 & 5.1445 & 4.8410 & 5.1453 & 5.1603 & 5.2343 & 5.0618\end{array}$ $\begin{array}{llllllllllllllllllll}\hat{c} & 1.9985 & 2.0043 & 1.9983 & 1.9988 & 2.0022 & 1.9992 & 3.9969 & 4.0087 & 3.9966 & 3.9976 & 4.0044 & 3.9985 & 7.9939 & 8.0174 & 7.9932 & 7.9952 & 8.0088 & 7.9970\end{array}$

$\begin{array}{lllllllllllllllllllllll}100 & \hat{k} & 5.0712 & 4.8832 & 5.0700 & 5.0799 & 4.9754 & 5.0289 & 5.0712 & 4.8832 & 5.0700 & 5.0799 & 4.9754 & 5.0289 & 5.0712 & 4.8832 & 5.0700 & 5.0799 & 4.9754 & 5.0289\end{array}$ 
Table 2: The averages of the MSEs of the obtained estimations for two-parameter Weibull Distribution according to different parameter estimation methods

\begin{tabular}{|c|c|c|c|c|c|c|c|c|c|c|c|c|c|c|c|c|c|c|c|}
\hline $\boldsymbol{k}$ & $n$ & \multicolumn{6}{|c|}{$c=2$} & \multicolumn{6}{|c|}{$c=\mathbf{4}$} & \multicolumn{6}{|c|}{$c=8$} \\
\hline \multirow{2}{*}{1.2} & 30 & 0.0708 & 0.0836 & 0.0749 & 0.0830 & 0.1451 & 0.0699 & 0.2234 & 0.2591 & 0.2304 & 0.2424 & 0.4120 & 0.2243 & 0.8338 & 0.9615 & 0.8522 & 0.8798 & 1.4796 & 0.8421 \\
\hline & 100 & 0.0206 & 0.0257 & 0.0223 & 0.0249 & 0.0386 & 0.0209 & 0.0677 & 0.0782 & 0.0706 & 0.0745 & 0.1132 & 0.0686 & 0.2561 & 0.2885 & 0.2637 & 0.2731 & 0.4119 & 0.2591 \\
\hline \multirow{3}{*}{3} & 10 & 0.7032 & 0.4917 & 0.6980 & 0.7987 & 1.9207 & 0.5279 & 0.7768 & 0.5703 & 0.7716 & 0.8736 & 2.0311 & 0.6025 & 1.0711 & 0.8849 & 1.0660 & 1.1733 & 2.4724 & 0.9010 \\
\hline & 30 & 0.1325 & 0.1654 & 0.1346 & 0.1952 & 0.3637 & 0.1257 & 0.1570 & 0.1921 & 0.1591 & 0.2206 & 0.4032 & 0.1504 & 0.2550 & 0.2990 & 0.2572 & 0.3223 & 0.5611 & 0.2489 \\
\hline & 100 & 0.0333 & 0.0538 & 0.0338 & 0.0546 & 0.0895 & 0.0341 & 0.0408 & 0.0620 & 0.0414 & 0.0625 & 0.1012 & 0.0417 & 0.0709 & 0.0948 & 0.0715 & 0.0942 & 0.1481 & 0.0719 \\
\hline \multirow{4}{*}{5} & 10 & 1.8943 & 1.3024 & 2.0788 & 2.1583 & 5.2464 & 1.4794 & 1.9213 & 1.3305 & 2.1058 & 2.1856 & 5.2861 & 1.5064 & 2.0292 & 1.4429 & 2.2140 & 2.2950 & 5.4447 & 1.6145 \\
\hline & 30 & 0.3483 & 0.4379 & 0.3965 & 0.5217 & 0.9785 & 0.3477 & 0.3572 & 0.4475 & 0.4054 & 0.5309 & 0.9925 & 0.3566 & 0.3927 & 0.4857 & 0.4410 & 0.5676 & 1.0486 & 0.3922 \\
\hline & 50 & 0.1852 & 0.2734 & 0.2136 & 0.2997 & 0.5992 & 0.1965 & 0.1906 & 0.2791 & 0.2190 & 0.3053 & 0.6075 & 0.2018 & 0.2120 & 0.3023 & 0.2405 & 0.3276 & 0.6406 & 0.2233 \\
\hline & 100 & 0.0864 & 0.1427 & 0.0980 & 0.1452 & 0.2390 & 0.0935 & 0.0891 & 0.1457 & 0.1007 & 0.1481 & 0.2433 & 0.0962 & 0.1000 & 0.1574 & 0.1116 & 0.1595 & 0.2601 & 0.1070 \\
\hline
\end{tabular}




\section{Results and Discussion}

The wind speed $(\mathrm{m} / \mathrm{h})$ data used to determine the wind potential of Meşelik Region of Eskişehir with Weibull distribution have been gathered $(\mathrm{m} / \mathrm{h})$ in 10-minute intervals through measuring devices installed 10 meters above the ground in Meşelik Campus of Eskişehir Osmangazi University. In the data measurement station, wind blowing directions are also determined via wind direction monitoring device installed 27 meters above the ground. As it is commonly used in wind energy studies, sectors are created as 30-degree slices, and a wind rose graph has been presented in Figure 2 in which wind blowing percentages from each sector are shown graphically.
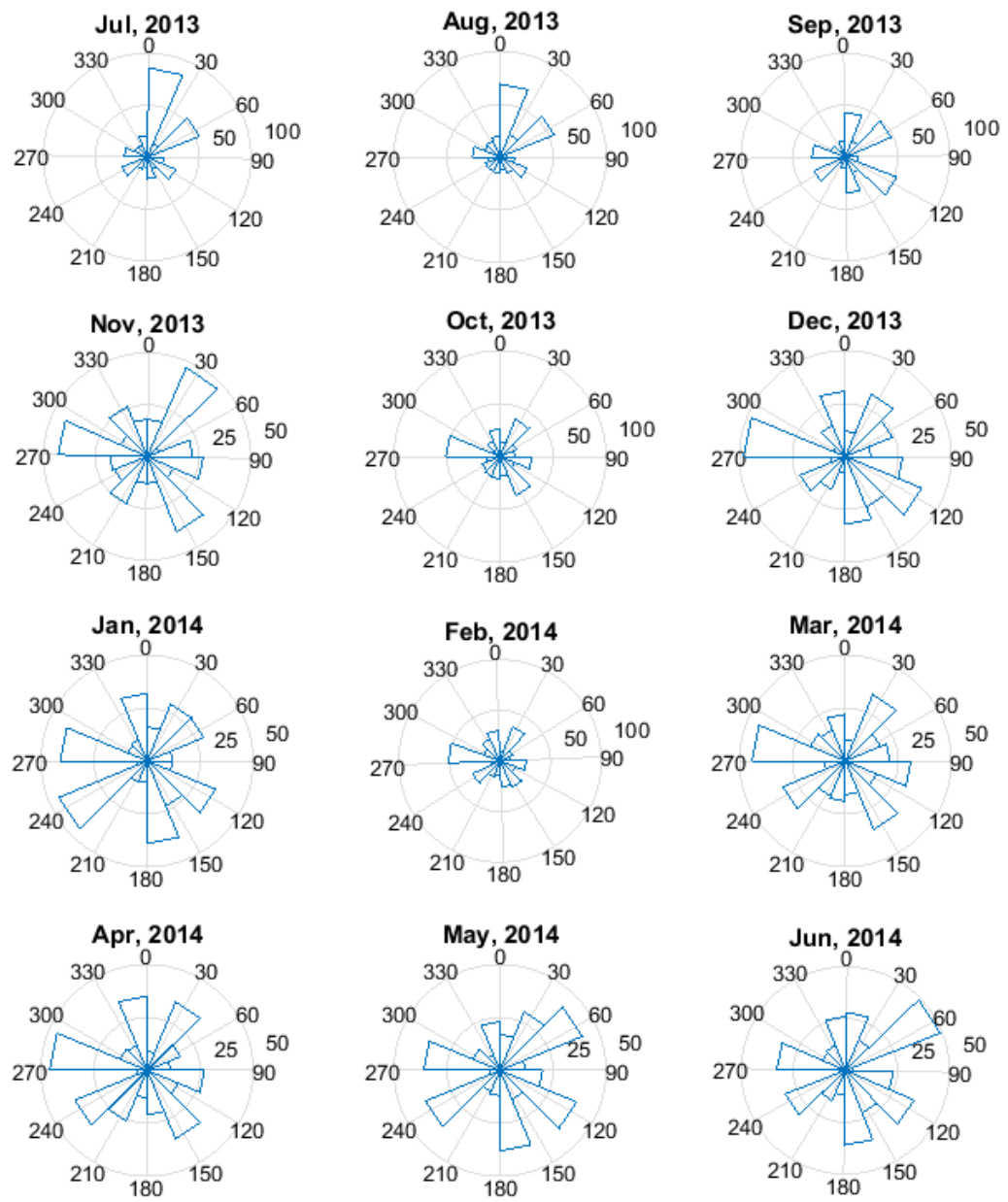

Figure 2: Monthly wind directions and wind rose graphs of frequencies

Examining Figure 2; it is observed that powerful wind directions vary according to the months of the year. In July and August, the most powerful wind direction is north while in September, it is South-East. While the most powerful wind direction in October, December, February, March, April, and June is west, it is South-West in January.

In the analysis of the wind potential of Meşelik Region of Eskişehir with Weibull distribution, MLE has been obtained by sticking to the results of distribution parameters simulation. RMSE and $R^{2}$ performance values have been presented in Table 3 in order to evaluate the fit between parameter estimations obtained by the modeling of monthly wind speeds according to two-parameter Weibull distribution, wind characteristics based on observation, wind characteristics based on two-parameter Weibull distribution, and the modeling of wind speeds with twoparameter Weibull distribution. Performance measures, RMSE and $R^{2}$, which show the fit between the Weibull distribution and the modeling of wind speed $(\mathrm{m} / \mathrm{h})$ data, have been obtained through equations below. 


$$
\begin{gathered}
R M S E=\sqrt{\frac{\sum_{i=1}^{n}\left(P_{i}-F_{i}\right)^{2}}{n-2}} \\
R^{2}=1-\frac{\sum_{i=1}^{n}\left(P_{i}-F_{i}\right)^{2}}{\sum_{i=1}^{n}\left(P_{i}-\bar{P}\right)^{2}}, \quad 0 \leq R^{2} \leq 1
\end{gathered}
$$

The term $P_{i}$ in the equation shows the empirical cumulative distribution function value and the term $F_{i}$ indicates the cumulative distribution function value according to two-parameter Weibull distribution. The lower RMSE and higher $R^{2}$ value indicates a good fit in the modeling.

Table 3: The parameter estimates (with confidence interval), the wind characteristics in terms of actual and two-

\begin{tabular}{|c|c|c|c|c|c|c|c|c|c|c|c|c|c|c|}
\hline \multirow[t]{2}{*}{ Months } & \multicolumn{3}{|c|}{ Scale } & \multicolumn{3}{|c|}{ shape } & \multicolumn{2}{|c|}{ Mean } & \multicolumn{2}{|c|}{$\begin{array}{c}\text { Std. } \\
\text { Deviation }\end{array}$} & \multicolumn{2}{|c|}{ Power } & \multicolumn{2}{|c|}{ Fitting } \\
\hline & $\widehat{C}_{\text {low }}$ & $\widehat{\boldsymbol{C}}$ & $\widehat{C}_{u p}$ & $\widehat{\boldsymbol{k}}_{\text {low }}$ & $\widehat{\boldsymbol{k}}$ & $\widehat{\boldsymbol{k}}_{u p}$ & Act & Wbl & Act & Wbl & Act & Wbl & $\mathbf{R}^{2}$ & RMSE \\
\hline Jul 2013 & 4.06 & 4.12 & 4.17 & 2.28 & 2.34 & 2.39 & 3.65 & 3.65 & 1.66 & 1.66 & 49.56 & 49.38 & 0.996 & 0.003 \\
\hline Aug 2013 & 3.61 & 3.66 & 3.71 & 2.23 & 2.28 & 2.34 & 3.24 & 3.24 & 1.50 & 1.50 & 35.56 & 35.19 & 0.997 & .003 \\
\hline Sep 2013 & 3.25 & 3.30 & 3.35 & 2.06 & 2.11 & 2.16 & 2.93 & 2.93 & 1.46 & 1.46 & 27.92 & 27.85 & 0.998 & 0.002 \\
\hline Nov 2013 & 3.29 & 3.35 & 3.41 & 1.72 & 1.76 & 1.80 & 2.98 & 2.98 & 1.77 & 1.75 & 37.64 & 35.74 & 0.997 & 0.003 \\
\hline Oct 2013 & 2.76 & 2.80 & 2.85 & 1.83 & 1.87 & 1.92 & 2.49 & 2.49 & 1.38 & 1.38 & 18.98 & 19.30 & 0.999 & 0.002 \\
\hline Dec 2013 & 3.15 & 3.20 & 3.25 & 1.95 & 2.00 & 2.05 & 2.84 & 2.83 & 1.47 & 1.48 & 25.94 & 26.67 & 0.997 & 0.003 \\
\hline Jan 2014 & 3.14 & 3.19 & 3.25 & 1.77 & 1.81 & 1.85 & 2.84 & 2.84 & 1.62 & 1.62 & 30.26 & 29.73 & 0.997 & 0.003 \\
\hline Feb 2014 & 2.96 & 3.01 & 3.06 & 1.85 & 1.89 & 1.94 & 2.67 & 2.67 & 1.47 & 1.47 & 23.56 & 23 & 0.999 & .002 \\
\hline Mar 2014 & 3.55 & 3.61 & 3.67 & 1.87 & 1.91 & 1.96 & 3.20 & 3.21 & 1.75 & 1.74 & 41.87 & 40.30 & 0.998 & 0.002 \\
\hline Apr 2014 & 3.29 & 3.35 & 3.41 & 1.75 & 1.79 & 1.83 & 2.98 & 2.98 & 1.74 & 1.72 & 35.84 & 34.92 & 0.998 & 0.003 \\
\hline May 2014 & 3.44 & 3.50 & 3.56 & 1.73 & 1.77 & 1.81 & 3.11 & 3.11 & 1.84 & 1.82 & 42.15 & 40.43 & 0.998 & 0.002 \\
\hline Jun 2014 & 3.37 & 3.43 & 3.48 & 1.86 & 1.91 & 1.95 & 3.04 & 3.04 & 1.67 & 1.66 & 35.34 & 34.54 & 0.998 & 0.003 \\
\hline
\end{tabular}
parameter Weibull distribution model, and the goodness of fitting performance values

Examining Table 3, very lower RMSE values and higher $R^{2}$ values indicates that the fit in the modeling of wind speed with Weibull distribution is quite good. Moreover, the fit between observation-based wind characteristics and characteristics based on parameter estimations of two-parameter Weibull distributions indicates that the modeling is quite successful. LM estimates, $\mathrm{R}^{2}$ and RMSE values of two-parameter Weibull distribution for wind speeds are given in Table 4 in order to compare the MLE and LM estimates in terms of goodness of fitting performance values.

Table 4: LM estimates of two-parameter Weibull distribution and the goodness of fitting performance values

\begin{tabular}{ccccc}
\hline Months & $\widehat{\boldsymbol{C}}$ & $\widehat{\boldsymbol{k}}$ & $\mathbf{R}^{\mathbf{2}}$ & $\mathbf{R M S E}$ \\
\hline Jul 2013 & 4.114 & 2.356 & 0.996 & 0.003 \\
Aug 2013 & 3.652 & 2.335 & 0.997 & 0.003 \\
Sep 2013 & 3.303 & 2.121 & 0.998 & 0.002 \\
Nov 2013 & 3.351 & 1.816 & 0.998 & 0.003 \\
Oct 2013 & 2.804 & 1.862 & 0.999 & 0.002 \\
Dec 2013 & 3.205 & 1.991 & 0.997 & 0.003 \\
Jan 2014 & 3.197 & 1.850 & 0.997 & 0.003 \\
Feb 2014 & 3.011 & 1.889 & 0.999 & 0.002 \\
Mar 2014 & 3.611 & 1.967 & 0.999 & 0.002 \\
Apr 2014 & 3.347 & 1.809 & 0.998 & 0.003 \\
May 2014 & 3.495 & 1.800 & 0.998 & 0.002 \\
Jun 2014 & 3.423 & 1.933 & 0.998 & 0.002 \\
\hline
\end{tabular}

When the goodness of fitting performance values in Table 3 and Table 4 were examined, it was seen that the fit performances of MLE and LM estimates are quite successful and similar. Probability density curves of twoparameter Weibull distribution with histograms of monthly wind speed in Meşelik region of Eskişehir have been given in Figure 3. 

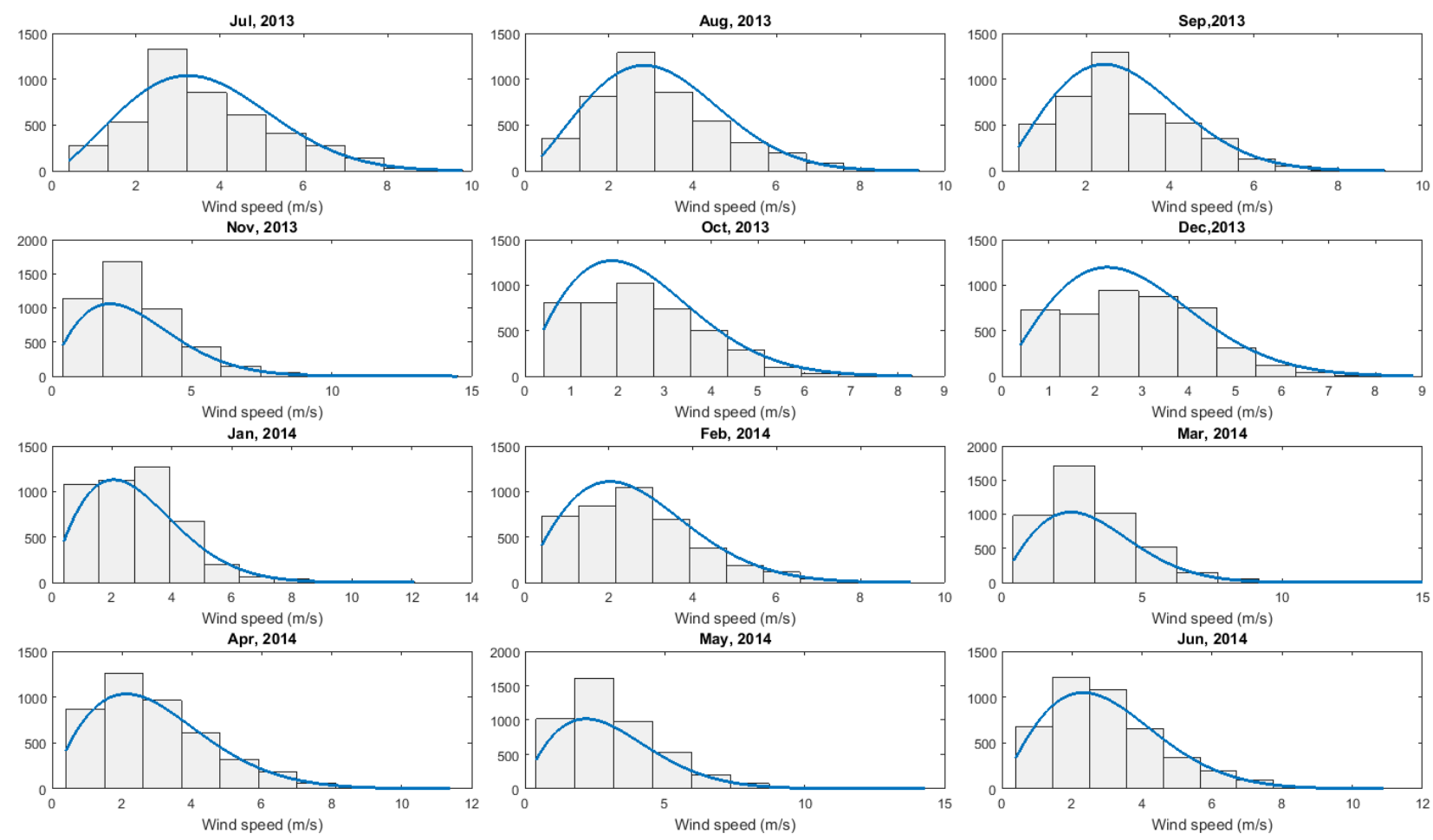

Figure 3: Wind speed histograms and the probability density curves based on two-parameter Weibull distribution

Examining the mean wind speeds calculated according to two-parameter Weibull distributions in Table 3; the highest mean wind speed is in July with $3.64788 \mathrm{~m} / \mathrm{h}$ and the lowest mean wind speed is in October with 2.48855 $\mathrm{m} / \mathrm{h}$. The concordance between monthly wind speed values observed in Meşelik region of Eskişehir and wind power $\left(\mathrm{W} / \mathrm{m}^{2}\right)$ calculated according to Weibull distribution is presented in Figure 4. In the Meşelik region of Eskişehir, the highest wind power that could be obtained according to two-parameter Weibull distribution is in July with 49.38295 $\left(\mathrm{W} / \mathrm{m}^{2}\right)$ and the lowest wind power is in October with $19.30044\left(\mathrm{~W} / \mathrm{m}^{2}\right)$.

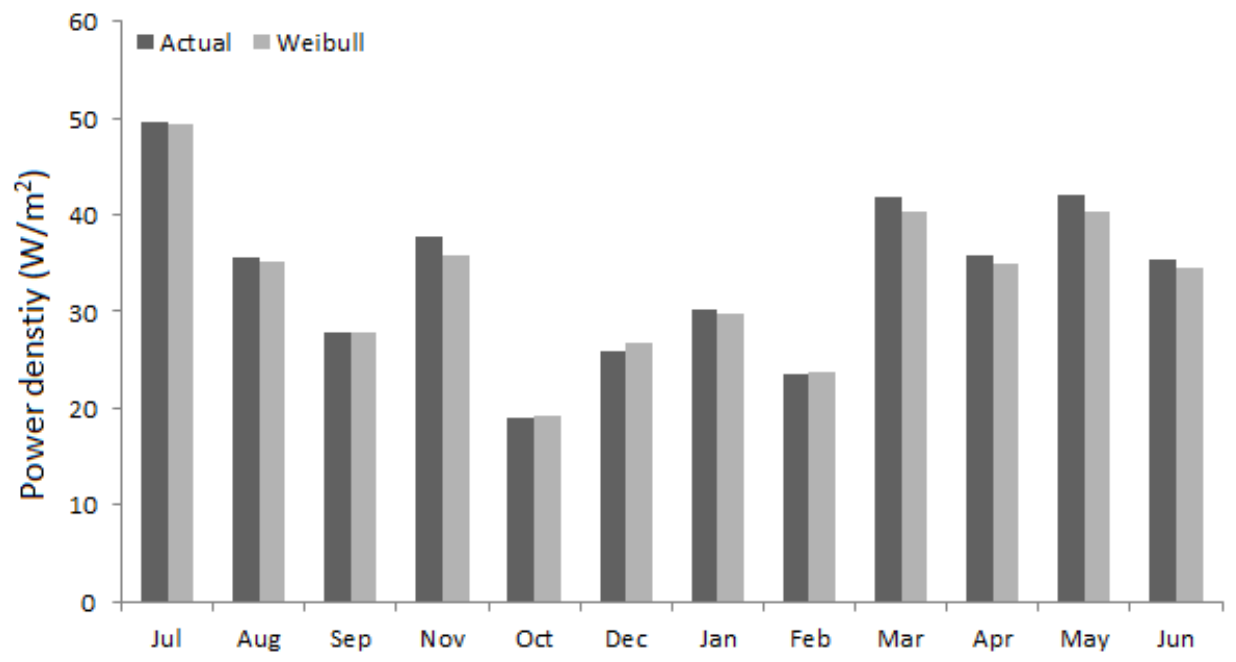

Figure 4: Comparison of observed wind power densities with wind power densities calculated based on twoparameter Weibull distribution 


\section{Conclusions}

Average wind speed $(\mathrm{m} / \mathrm{h})$ data obtained in 10-minute intervals via data measuring devices installed 10 meters above the ground in Meşelik Campus of Eskişehir Osmangazi University are modeled with two-parameter Weibull distribution and the wind energy potential of the region has been statistically analyzed. Six different parameter estimation methods have been compared through a simulation study in order to determine the most suitable estimation method in Weibull distribution parameters estimation. In the comparison of parameter estimation methods, MSE and MAPE criteria have been taken into consideration. As a result of the comparison, LM and MLE have been found as the most successful methods in small and large sample sizes, respectively. In the simulation study, LM has been found as the best alternative parameter estimation method for MLE, which is the most commonly, used method in the modeling of wind speed data with Weibull distribution. The wind energy potential evaluation of the region is performed based on the monthly wind speed $(\mathrm{m} / \mathrm{h})$ data. The concordance of the monthly wind speed data of the district in the modeling with two-parameter Weibull distribution has been evaluated based on RMSE and $R^{2}$ criteria, and as a result of the evaluation, it has been found as quite good. The fit between wind characteristics based on observed wind speed $(\mathrm{m} / \mathrm{h})$ and wind characteristics based on two-parameter Weibull distribution has also been found as good. In the region, the highest average wind power density has been obtained in July with a value of $49.38295\left(\mathrm{~W} / \mathrm{m}^{2}\right)$ while the lowest average wind power density has been obtained in October with a value of $19.30044\left(\mathrm{~W} / \mathrm{m}^{2}\right)$. Future researches about the estimation of wind potential of Meşelik (Eskişehir) region could compare wind speeds through devices installed at different heights.

\section{Acknowledgements}

The authors gratefully acknowledge Eskişehir Osmangazi University Scientific Research Projects Commission for the financial support of this study through the project number 201015023.

\section{References}

1. Akdağ S. A, Güler Ö. (2018). Alternative Moment Method for wind energy potential and turbine energy output estimation. Renewable Energy 2018; 120: 69-77.

2. Ali S., Lee S. M, Jang C. M. (2018). Statistical analysis of wind characteristics using Weibull and Rayleigh distributions in Deokjeok-do Island - Incheon, South Korea. Renewable Energy, 123, 652-663.

3. Aras H. (2003).Wind energy status and its assessment in Turkey. Renewable Energy, 28(14), $2213-2220$.

4. Baseer M. A., Meyer J. P., Rehman S., Alam M. M. (2017). Wind power characteristics of seven data collection sites in Jubail, Saudi Arabia using Weibull parameters. Renewable Energy, 102, 35-49.

5. Carta J. A., Ramírez P, Velázquez S. (2009) A review of wind speed probability distributions used in wind energy analysis. Renewable and Sustainable Energy Reviews, 13(5), 933-955.

6. Erisoglu U., Erisoglu M. (2014). L-Moments Estimations for Mixture of Weibull Distributions. Journal of Data Science, 12, 69-85.

7. Genc A., Erisoglu M., Pekgor A., Oturanc G., Hepbasli A., Ulgen K. (2005). Estimation of Wind Power Potential Using Weibull Distribution. Energy Sources, 27(9), 809-822.

8. Novoa C. H., Pérez I. A., Sánchez M. L., García M. Á., Pardo N., Duque B. F.(2017). Wind speed description and power density in northern Spain. Energy, 138, 967-76.

9. Kantar Y. M., Usta I., Arik I., Yenilmez I. (2018). Wind speed analysis using the Extended Generalized Lindley Distribution. Renewable Energy, 118, 1024-1030.

10. Karakoca A., Erisoglu U., Erisoglu M. (2015). A comparison of the parameter estimation methods for bimodal mixture Weibull distribution with complete data. Journal of Applied Statistics, 42(7), 1472-1489.

11. Marks N. B. (2005). Estimation of Weibull parameters from common percentiles. Journal of Applied Statistics, 32(1), 17-24.

12. Malvaldi, A., Weiss S., Infield D., Browell J., Leahy P., Foley A. M. (2017). A spatial and temporal correlation analysis of aggregate wind power in an ideally interconnected Europe. Wind Energy, 20(8), 1315-1329.

13. Shoaib, M., Siddiqui I., Amir Y.M., Rehman S.U. (2017). Evaluation of wind power potential in Baburband (Pakistan) using Weibull distribution function. Renewable and Sustainable Energy Reviews, 70, $1343-1351$.

14. Soulouknga M. H., Doka S. Y., Revanna N., Djongyang N., Kofane T. C. (2018). Analysis of wind speed data and wind energy potential in Faya-Largeau, Chad, using Weibull distribution. Renewable Energy, 121, 1-8.

15. Sweeney C., Bessa R. J., Browell J., Pinson P. (2020). The future of forecasting for renewable energy. Wiley Interdisciplinary Reviews: Energy and Environment, 9(2), e365. 
16. Teimouri M., Hoseini S. M., Nadarajah S. (2013). Comparison of estimation methods for the Weibull distribution. Statistics, 47(1), 93-109.

17. Wais P. (2017). Two and three-parameter Weibull distribution in available wind power analysis. Renewable Energy, 103, 15-29.

18. Wang F. K., Keats J. B. (1995). Improved percentile estimation for the two-parameter Weibull distribution. Microelectronics Reliability, 35(6), 883-892. 